\title{
Gas-Liquid Flow in a Vertical Pipe Equipped with a Double Helical Swirl Separator Element
}

\author{
Ryan Anugrah Putra ${ }^{\mathrm{a}, 1, *}$, Akhlisa Nadiantya Aji Nugroho ${ }^{\mathrm{a}, 2}$ Aditya Ramadhona ${ }^{\mathrm{a}, 3}$ \\ Erick Wisnu Kuncoro Baroto ${ }^{\mathrm{a}, 4}$
${ }^{a}$ Department of Mechanical \& Industrial Engineering, Faculty of Engineering, Universitas Gadjah Mada, Jalan Grafika No. 2, 55281 Yogyakarta, Indonesia
Iryan.putra@ugm.ac.id*; ${ }^{2}$ akhlisa.nadiantya.a@mail.ugm.ac.id; ${ }^{3}$ aditya.ramadhona@mail.ugm.ac.id; 4eriwk321@gmail.com
* corresponding author

ARTICLE INFO

Article history:

Accepted

Keywords:

Swirl separator

CFD

Gas-liquid

Rotating flow

Inline separator

\section{ABSTRACT}

Two different gas-liquid flow behavior downstream a double helical swirl element inside a vertical pipe was observed in our preliminary experiment. The present Computational Fluid Dynamics (CFD) study confirms that the dynamics of gas-liquid flows inside the swirl separator is highly influenced by the liquid superficial velocity. The separation behavior in this work at a liquid superficial velocity of 0.1 $\mathrm{m} / \mathrm{s}$ was the worst both axially and radially since the gas core cannot be sustained up to the outlet. The separation condition was improved by the increase of the liquid superficial velocity. The best separation condition in this study was achieved at the liquid superficial velocity of $1.0 \mathrm{~m} / \mathrm{s}$ where the dense gas core can be maintained up to the outlet.

Copyright (C) 2020 Politeknik Aceh Selatan. All rights reserved.

\section{Introduction}

If the liquid height inside a storage is not sufficiently high, there is a possibility that gas will be sucked by the pump into the pipe system [1]. The gas entrainment into a system may cause several problems e.g. the gas entrainment into waterline system in the Statoil Statfjord-B platform leads to problems with vibrations and unstable flare system [2]. The entered gas in the pipe system can be separated using a swirl flow concept where a static swirl element can be used to generate centrifugal force to separate between the liquid and gas phases [2]-[8]. Swirl elements with different geometries can be found in the open literature e.g. [9]. Figure 1 shows a double helical swirl element [9] used in our preliminary experiment at the Laboratory of Fluid Mechanics, Department of Mechanical and Industrial Engineering, Universitas Gadjah Mada. The element was placed in a vertical pipe to generate swirling flow for the separation between gas and liquid.

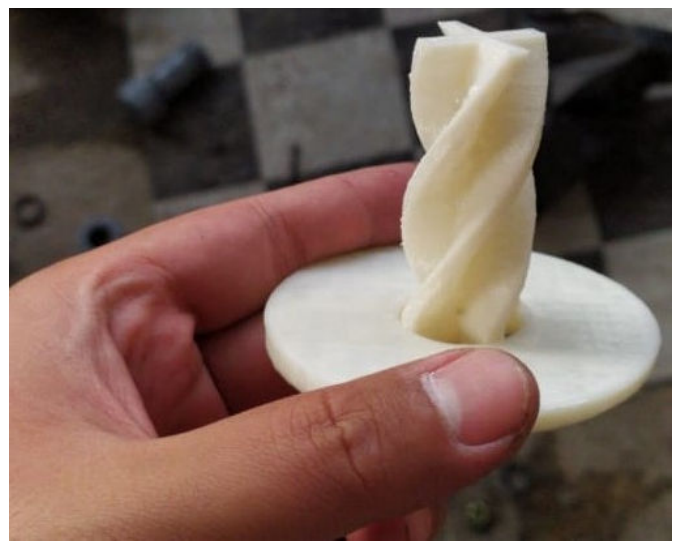

Fig. 1. A double helical swirl separator element [9]. 
In a certain operating condition in the experiment, the gas was accumulated in the center of the pipe forming a gas core as shown in Figure 2a which is a favorable separation condition. However, in other operating condition, the unwanted separation condition where the gas core failed to be formed downstream the element leading to the dispersion of the gas bubbles in the pipe was observed (see Figure 2b). To have a more detail description on gas-liquid flows behavior in the swirl separator, two-phase Computational Fluid Dynamics (CFD) was used in this work. Since the liquid superficial velocity was reported to have a significant role in the gas-liquid characteristic inside a static mixer [10], [11] thus the liquid superficial velocity was varied in the present CFD simulations to investigate its influence on the separation behavior.

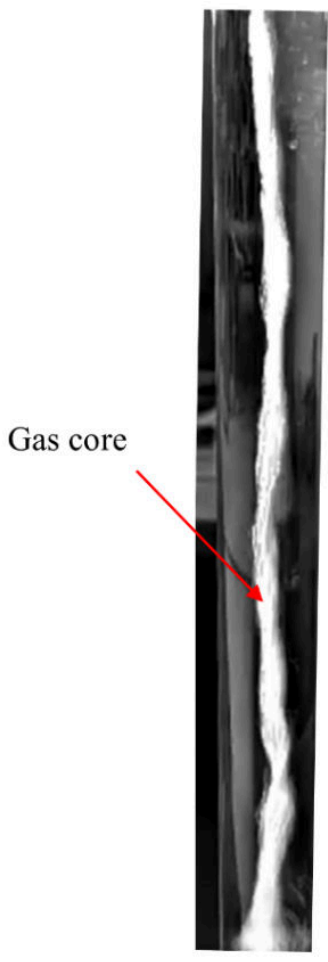

(a)

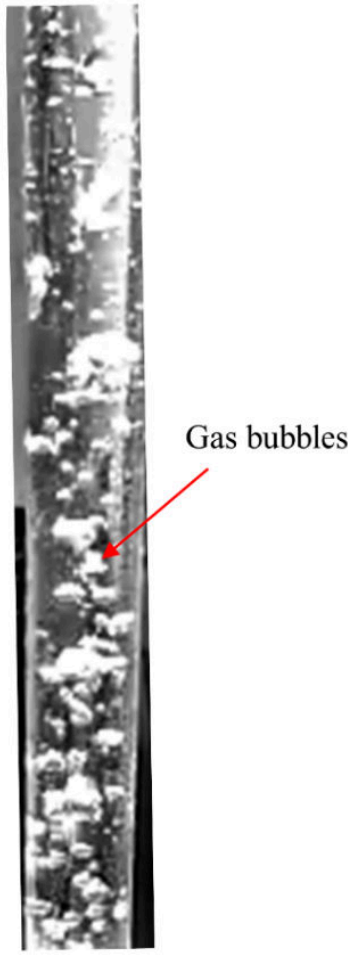

(b)

Fig. 2. Gas-liquid flow downstream the element: (a) gas core formation and (b) bubbly flow.

\section{Method}

The computational domain used in this work is shown in Fig. 3a. The domain consists of a vertical pipe with diameter of $24 \mathrm{~mm}$ and length of $500 \mathrm{~mm}$. The double helical swirl separator element with diameter (D) of $24 \mathrm{~mm}$ and length (L) of $52 \mathrm{~mm}$ (see Fig. 3b) is placed at an axial distance of $100 \mathrm{~mm}$ from the inlet of the vertical pipe. To investigate the separation characteristic, the numerically obtained gas distribution was evaluated at several cross-sectional planes that are indicated by P1-P6 in Fig. 3a.

In the present work, CFD simulations using the Euler-Euler model were used. Water was defined as the liquid continuous phase while air was defined as the dispersed phase having a uniform diameter of $0.5 \mathrm{~mm}$. Two set of continuity and momentum equations (i.e., one set for each phase) given in (1) and (2), respectively were solved across the fixed computational cells [12]:

$$
\begin{aligned}
& \frac{\partial}{\partial t}\left(\alpha_{j} \rho_{j}\right)+\nabla \cdot\left(\alpha_{j} \rho_{j} \boldsymbol{u}_{j}\right)=S_{j} \\
& \frac{\partial}{\partial t}\left(\alpha_{j} \rho_{j} \boldsymbol{u}_{j}\right)+\nabla \cdot\left(\alpha_{j}\left(\rho_{\alpha} \boldsymbol{u}_{j} \times \boldsymbol{u}_{j}\right)\right)=-\alpha_{j} \nabla p+\nabla \cdot\left(\alpha_{j} \mu_{j}\left(\nabla \boldsymbol{u}_{j}+\left(\nabla \boldsymbol{u}_{j}\right)^{T}\right)\right)+\boldsymbol{M}_{j}+S_{M j}
\end{aligned}
$$

The density, the volume fraction, the velocity vector, the time, the mass source, the momentum sources due to external body forces and the pressure are represented by $\alpha_{j}, \rho_{j}, \boldsymbol{u}_{j}, t, S_{j}, S_{M j}$ and $p$, respectively [12]. The sum of the bubble forces represented by $\boldsymbol{M}_{j}$ in (2) can be calculated as [12]:

$$
\boldsymbol{M}_{j}=\boldsymbol{F}_{\text {drag }}+\boldsymbol{F}_{\text {lift }}+\boldsymbol{F}_{\text {wall }}+\boldsymbol{F}_{T D}+\boldsymbol{F}_{V M}
$$


The above equation shows that drag force $\boldsymbol{F}_{\text {drag }}$, lift force $\boldsymbol{F}_{\text {lift }}$, wall lubrication force $\boldsymbol{F}_{\text {wall }}$, turbulent dispersion force $\boldsymbol{F}_{T D}$ and virtual mass force $\boldsymbol{F}_{V M}$ were considered in this study. The selected models for those bubble forces are listed in Table 1. For the continuous phase turbulence model, the $\mathrm{k}-\omega$-based shear stress transport (SST) model proposed by [13] was used. As an addition, the bubble induced turbulence model proposed by [14] was used in the CFD simulations.

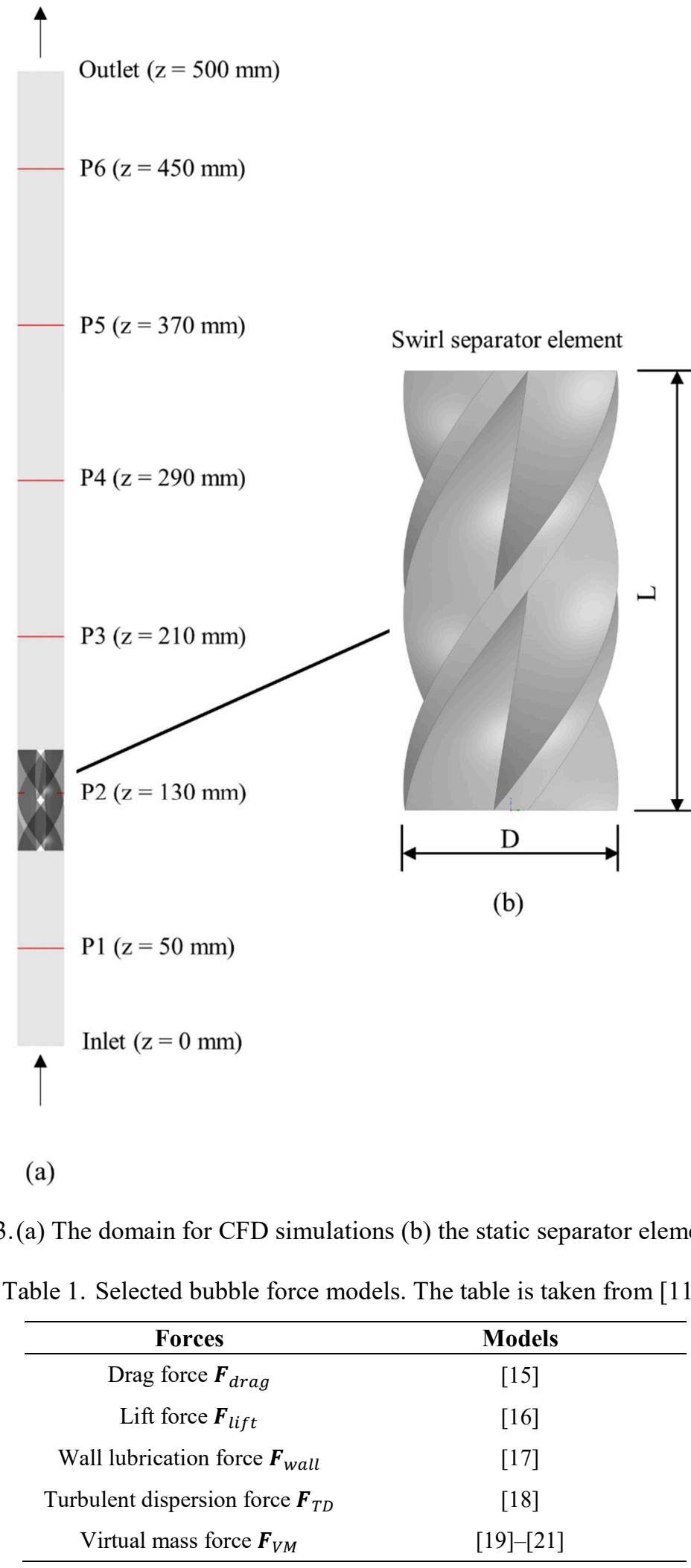


The CFD simulations were performed under the steady-state and adiabatic mode at different liquid superficial velocity (i.e. ranging from 0.1 to $1.0 \mathrm{~m} / \mathrm{s}$ ) while keeping the gas superficial velocity constant at $0.02 \mathrm{~m} / \mathrm{s}$. The corresponding liquid and gas velocities were defined as the inlet boundary condition. A pressure boundary condition was defined at the outlet while all other parts were defined as the no-slip wall. All CFD simulations were carried out using ANSYS CFX 19.2 Student Edition.

\section{Results and Discussion}

The gas volume fraction at the central axial plane for different liquid superficial velocity is shown in Fig. 4. The image shows that the axial gas distribution is highly influenced by the liquid superficial velocity $J_{L}$. For the lowest liquid superficial velocity used in this work (i.e. $J_{L}=0.1 \mathrm{~m} / \mathrm{s}$ ) the accumulation of the gas at the center of the pipe only occur in the region just downstream the element (see Fig. 4a). The gas core was relatively short and was not sustained up to the outlet. After a certain axial distance, the gas core was decayed leading to the re-dispersion of the gas phase throughout the pipe. Increasing to $J_{L}=0.2 \mathrm{~m} / \mathrm{s}$ leads to a longer gas core (see Fig. $4 \mathrm{~b}$ ). However, the strength of the rotation seems not enough to maintain the gas core leading to the decay of the gas core resulting in the re-mixing of gas and liquid phase which is not wanted in this separator. Increasing the liquid superficial velocity to $J_{L}=0.3 \mathrm{~m} / \mathrm{s}$ significantly improves the separation behavior. The gas accumulation at the center region of the pipe can be maintained up to the outlet (see Fig. 4c). Increasing further the liquid superficial velocity resulting in a better separation which is indicated with a denser gas core as shown in Fig. 4d. The best separation condition in this study was achieved at $J_{L}=$ $1.0 \mathrm{~m} / \mathrm{s}$ where the dense gas core sustains up to the outlet (see Fig. 4e).

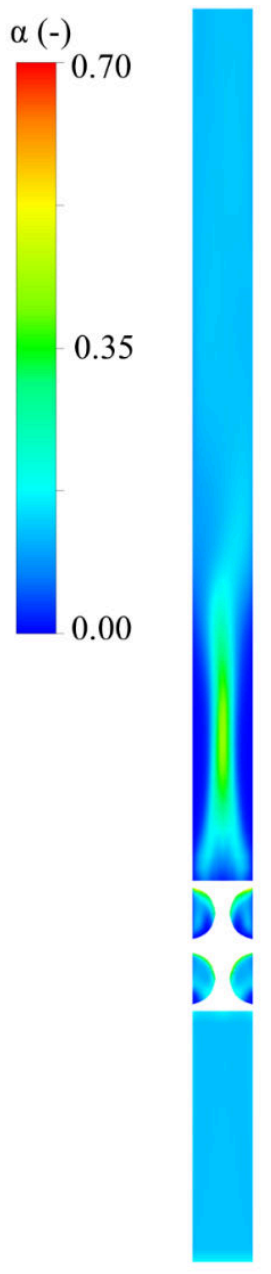

(a)

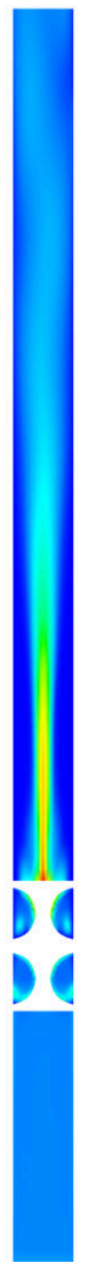

(b)

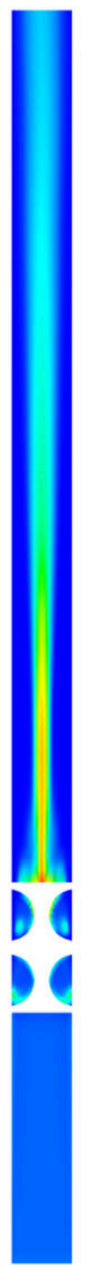

(c)
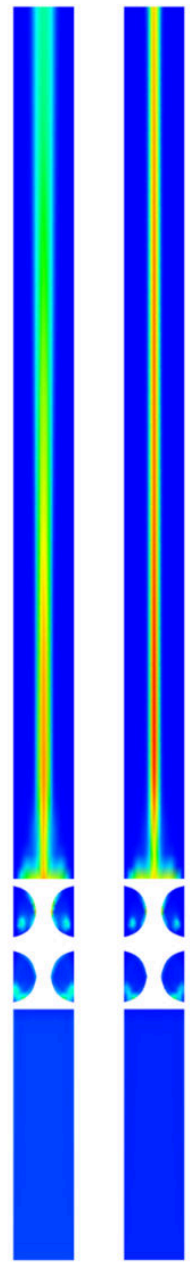

(d)

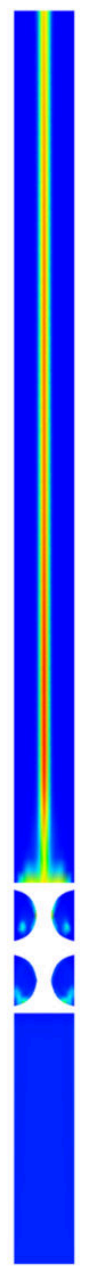

(e)

Fig. 4. Gas volume fraction on the central axial plane for different inlet liquid superficial velocities: (a) $0.1 \mathrm{~m} / \mathrm{s}$, (b) $0.2 \mathrm{~m} / \mathrm{s}$, (c) $0.3 \mathrm{~m} / \mathrm{s}$, (d) $0.5 \mathrm{~m} / \mathrm{s}$ and (e) $1.0 \mathrm{~m} / \mathrm{s}$. 
The streamlines of the liquid velocity for different $J_{L}$ are shown in Fig. 5 . For $J_{L}=0.1 \mathrm{~m} / \mathrm{s}$ the swirling streamlines exist only up to certain axial distance downstream the element (see Fig. 5a). The shape of these streamlines may explain the reason of the gas distribution shown in Fig. 4a. The gas core can be formed when the rotating flow is generated. The gas core may decay when the rotating flow is also decay which is indicated with a relatively straight streamlines shown in Fig. 5a. The swirling streamlines improves as the liquid superficial velocity increases similar to the phenomenon observed e.g. in [10], [11], [22]. In the case of $J_{L}=1.0 \mathrm{~m} / \mathrm{s}$, the highly swirling streamlines with the highest velocity (see Fig. 5e) leads to the most concentrated gas core shown in Fig. 4e resulting the best separation condition in this study.

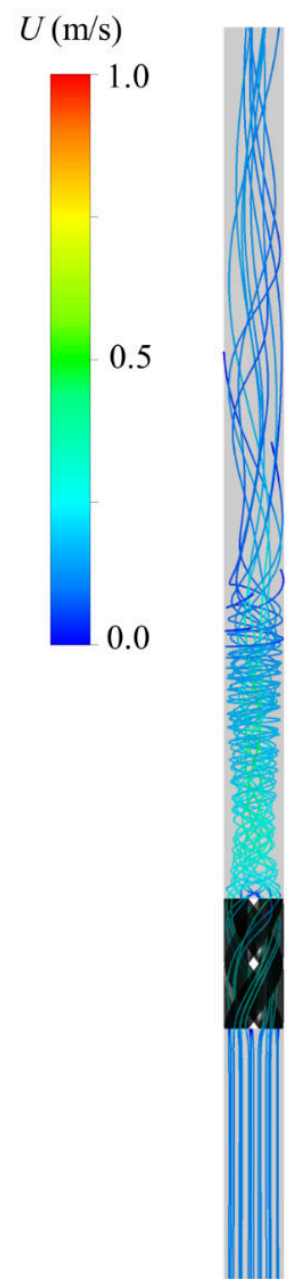

(a)

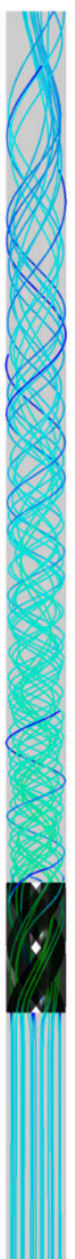

(b)

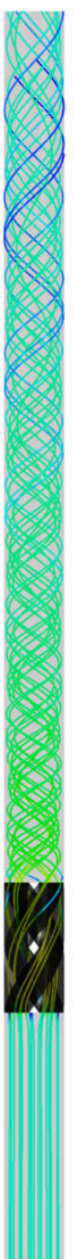

(c)

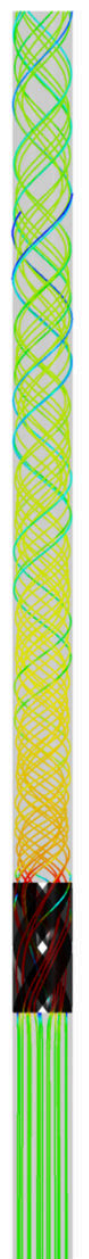

(d)

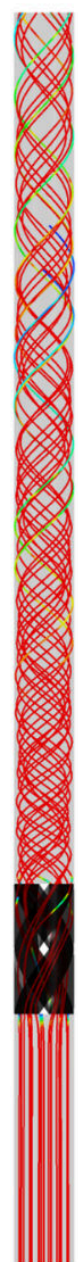

(e)

Fig. 5. Streamlines of the liquid velocity for different inlet liquid superficial velocities: (a) $0.1 \mathrm{~m} / \mathrm{s}$, (b) $0.2 \mathrm{~m} / \mathrm{s}$, (c) $0.3 \mathrm{~m} / \mathrm{s},(\mathrm{d}) 0.5 \mathrm{~m} / \mathrm{s}$ and (e) $1.0 \mathrm{~m} / \mathrm{s}$.

Fig. 6 shows the contour of gas fraction on several evaluation planes for different $J_{L}$. In the case of $J_{L}=0.1$ $\mathrm{m} / \mathrm{s}$ the gas is well distributed over the cross-sectional plane $\mathrm{P} 1$ which is located upstream the separator element (see Fig. 6a). The separation process has not yet started and the gas core has not yet formed at this region. The accumulation of gas in the center of the pipe due to the centrifugal force can be observed in P3. However, the gas is re-dispersed in P3 and well distributed at the remaining planes. The separation behavior is poor at this $J_{L}$. Increasing $J_{L}$ to $0.2 \mathrm{~m} / \mathrm{s}$ leads to the improvement in the separation as can be seen in P3-P6 of Fig. $6 \mathrm{~b}$. The gas is accumulated at the center region of the pipe downstream the element. However, the gas is re-dispersed in P5 and P6. A significant improvement of separation process can be observed at $J_{L}=0.3 \mathrm{~m} / \mathrm{s}$ where the gas is accumulated at the center of the pipe in P3-P6. However, the gas core is not sufficiently dense at this $J_{L}$. The best separation of gas and liquid phases is achieved at $J_{L}=1.0 \mathrm{~m} / \mathrm{s}$ where the dense gas core observed at P3-P6. 


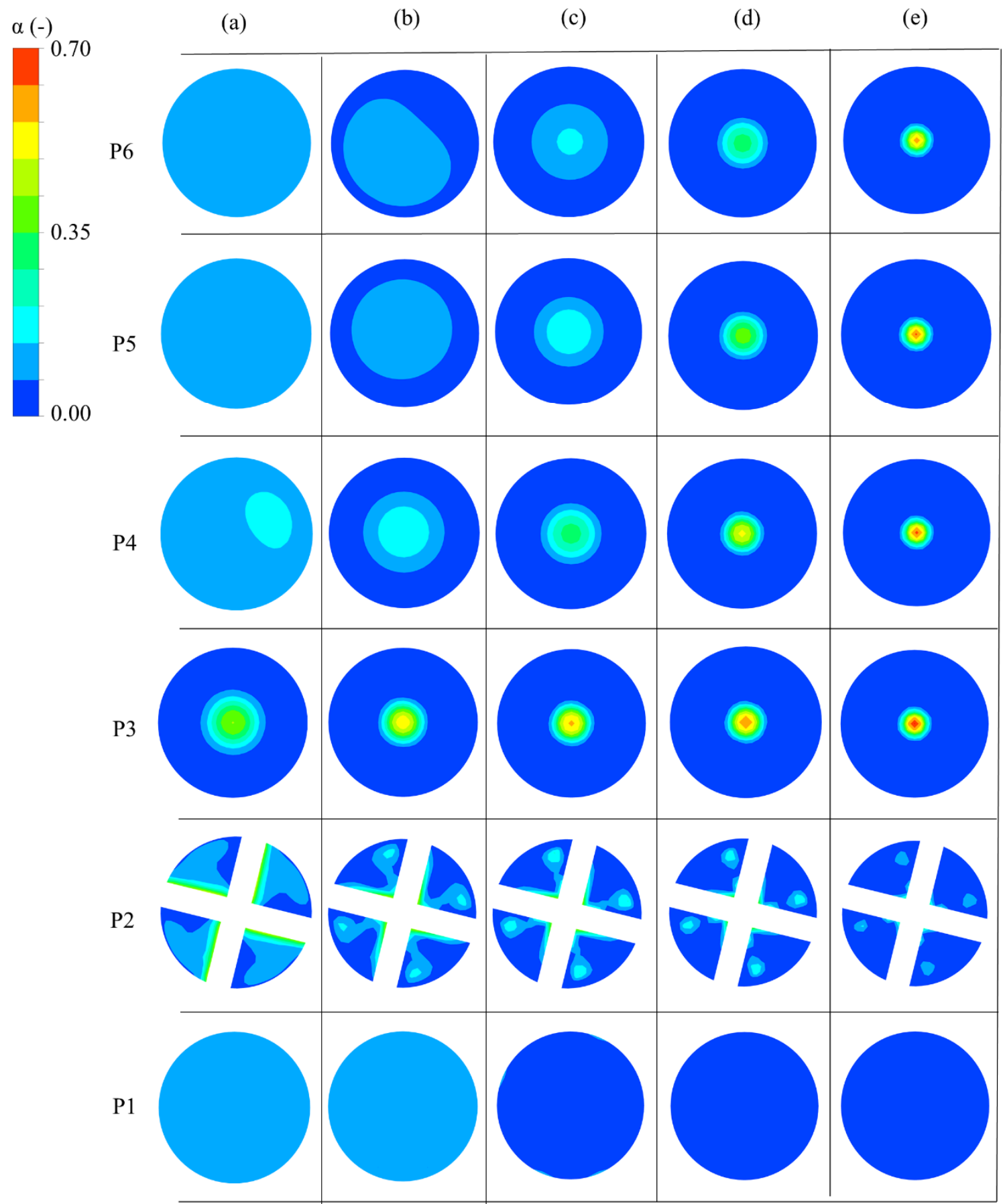

Fig. 6. Contours of gas volume fraction on several evaluation planes for different inlet liquid superficial velocities: (a) $0.1 \mathrm{~m} / \mathrm{s}$, (b) $0.2 \mathrm{~m} / \mathrm{s}$, (c) $0.3 \mathrm{~m} / \mathrm{s}$, (d) $0.5 \mathrm{~m} / \mathrm{s}$ and (e) $1.0 \mathrm{~m} / \mathrm{s}$.

\section{Conclusion}

The gas-liquid flows inside the swirl separator was observed in this study. The preliminary experiment shows that the flow characteristic downstream the element can be varied (i.e. either gas core or bubbly flow can be obtained). The CFD simulation shows that the liquid superficial velocity plays an important role on the flow characteristic. The gas core cannot be sustained up to the outlet in the case of $J_{L}<0.3 \mathrm{~m} / \mathrm{s}$. This behavior is highly related with the streamlines generated downstream the element. The best separation condition in this study is achieved at $J_{L}=1.0 \mathrm{~m} / \mathrm{s}$ where the dense gas core is sustained downstream the element up to the outlet. 


\section{Acknowledgment}

This research work is financed by the Faculty of Engineering, Universitas Gadjah Mada, Yogyakarta, Indonesia under a research grant of the Department of Mechanical and Industrial Engineering, Faculty of Engineering, Universitas Gadjah Mada, Yogyakarta, Indonesia with contract number: 417/UN1.FTK/SK/HK/2020.

\section{References}

[1] N. Yıldırım, F. Kocabaş, and S. C. Gülcan, "Flow-Boundary Effects on Critical Submergence of Intake Pipe," J. Hydraul. Eng., vol. 126, no. 4, pp. 288-297, Apr. 2000, doi: 10.1061/(ASCE)07339429(2000)126:4(288).

[2] rob schook and V. van Asperen, "Compact separation by means of inline technology," in SPE-93232MS, Kingdom of Bahrain, Jan. 2005, p. 7, doi: 10.2118/93232-MS.

[3] X. Luo, L. Yang, H. Yin, L. He, and Y. Lü, "A review of vortex tools toward liquid unloading for the oil and gas industry," Chem. Eng. Process. - Process Intensif., vol. 145, p. 107679, Nov. 2019, doi: 10.1016/j.cep.2019.107679.

[4] R. A. Putra, T. Schäfer, M. Neumann, and D. Lucas, "CFD studies on the gas-liquid flow in the swirl generating device," Nucl. Eng. Des., vol. 332, pp. 213-225, Jun. 2018, doi: 10.1016/j.nucengdes.2018.03.034.

[5] T. Matsubayashi, K. Katono, K. Hayashi, and A. Tomiyama, "Effects of swirler shape on swirling annular flow in a gas-liquid separator," Nucl. Eng. Des., vol. 249, pp. 63-70, Aug. 2012, doi: 10.1016/j.nucengdes.2011.05.036.

[6] H. Funahashi, K. Hayashi, S. Hosokawa, and A. Tomiyama, "Study on two-phase swirling flows in a gasliquid separator with three pick-off rings," Nucl. Eng. Des., vol. 308, pp. 205-213, Nov. 2016, doi: 10.1016/j.nucengdes.2016.08.030.

[7] J. Yin, Y. Ma, Y. Qian, and D. Wang, "Experimental investigation of the bubble separation route for an axial gas-liquid separator for TMSR," Ann. Nucl. Energy, vol. 97, pp. 1-6, Nov. 2016, doi: 10.1016/j.anucene.2016.06.018.

[8] B. Cai, J. Wang, L. Sun, N. Zhang, and C. Yan, "Experimental study and numerical optimization on a vane-type separator for bubble separation in TMSR," Prog. Nucl. Energy, vol. 74, pp. 1-13, Jul. 2014, doi: 10.1016/j.pnucene.2014.02.007.

[9] R. A. Putra, M. Neumann-Kipping, T. Schäfer, and D. Lucas, "Comparison of Gas-Liquid Flow Characteristics in Geometrically Different Swirl Generating Devices," Energies, vol. 12, no. 24, 2019, doi: 10.3390/en12244653.

[10] S. Rabha, M. Schubert, F. Grugel, M. Banowski, and U. Hampel, "Visualization and quantitative analysis of dispersive mixing by a helical static mixer in upward co-current gas-liquid flow," Chem. Eng. J., vol. 262, pp. 527-540, Feb. 2015, doi: 10.1016/j.cej.2014.09.019.

[11] R. A. Putra and A. N. A. Nugroho, "Numerical Simulation of the Gas-Liquid Flow Inside a Horizontal Static Mixer," J. Inotera, vol. 5, no. 2, Art. no. 2, Jul. 2020, doi: 10.31572/inotera.Vol5.Iss2.2020.ID104.

[12] ANSYS, “ANSYS CFX-Solver Theory Guide, Release 19.2." 2019.

[13] F. R. Menter, "Two-equation eddy-viscosity turbulence models for engineering applications," AIAA J., vol. 32, no. 8, pp. 1598-1605, Aug. 1994, doi: 10.2514/3.12149.

[14] Y. Sato and K. Sekoguchi, "Liquid velocity distribution in two-phase bubble flow," Int. J. Multiph. Flow, vol. 2, no. 1, pp. 79-95, Jun. 1975, doi: 10.1016/0301-9322(75)90030-0.

[15] M. Ishii and N. Zuber, "Drag coefficient and relative velocity in bubbly, droplet or particulate flows," AIChE J., vol. 25, no. 5, pp. 843-855, Sep. 1979, doi: 10.1002/aic.690250513.

[16] A. Tomiyama, H. Tamai, I. Zun, and S. Hosokawa, "Transverse migration of single bubbles in simple shear flows," Chem. Eng. Sci., vol. 57, no. 11, pp. 1849-1858, Jun. 2002, doi: 10.1016/S00092509(02)00085-4.

[17] S. P. Antal, R. T. Lahey, and J. E. Flaherty, "Analysis of phase distribution in fully developed laminar bubbly two-phase flow," Int. J. Multiph. Flow, vol. 17, no. 5, pp. 635-652, Sep. 1991, doi: 10.1016/03019322(91)90029-3.

[18] A. D. Burns, T. Frank, I. Hamill, and J.-M. Shi, "The Favre Averaged Drag Model for Turbulent Dispersion in Eulerian Multi-Phase Flows," 5th Int. Conf. Multiph. Flow ICMF-2004 Yokohama Jpn., 2004.

[19] T. R. Auton, J. C. R. Hunt, and M. Prud'Homme, "The force exerted on a body in inviscid unsteady nonuniform rotational flow," J. Fluid Mech., vol. 197, pp. 241-257, 1988, doi: 10.1017/S0022112088003246.

[20] J. Magnaudet, M. Rivero, and J. Fabre, "Accelerated flows past a rigid sphere or a spherical bubble. Part 1. Steady straining flow," J. Fluid Mech., vol. 284, pp. 97-135, 1995, doi: 10.1017/S0022112095000280.

[21] M. R. Maxey and J. J. Riley, "Equation of motion for a small rigid sphere in a nonuniform flow," Phys. Fluids, vol. 26, no. 4, pp. 883-889, Apr. 1983, doi: 10.1063/1.864230. 
[22] R. A. Putra, "Mixing Characteristics of Gas-Liquid Flow in a Static Mixer: A Numerical Study," Angkasa J. Ilm. Bid. Teknol., no. Submitted, 2020. 